\title{
THE RELATIONSHIP BETWEEN MACROPLASTIC AND LARGE-MICROPLASTIC ABUNDANCE IN THE NORTHERN COASTAL REGION OF WEST PENINSULAR MALAYSIA
}

\author{
Anisah Jessica Lee ${ }^{1^{*}}$ \\ ${ }^{1}$ Associate Professor, \\ Geoinformatic Unit, \\ Geography Section, \\ School of Humanities, \\ Universiti Sains Malaysia, \\ 11800 USM, Pulau Pinang, \\ Malaysia
}

\author{
Muhammad Fakruhayat Ab Rashid ${ }^{2}$ \\ ${ }^{2}$ Geoinformatic Unit, \\ Geography Section, \\ School of Humanities, \\ Universiti Sains Malaysia, \\ 11800 USM, Pulau Pinang, \\ Malaysia
}

*Corresponding author: Anisah Jessica Lee

\author{
Zaity Syazwani Mohd. Odli ${ }^{2,3}$ \\ ${ }^{2}$ Geoinformatic Unit, \\ Geography Section, \\ School of Humanities, \\ Universiti Sains Malaysia, \\ 11800 USM, Pulau Pinang, \\ Malaysia \\ ${ }^{3}$ School of Environmental Engineering, \\ Universiti Malaysia Perlis, \\ 02600 Arau, Perlis, \\ Malaysia
}

\author{
Muhammad Aslam Abdul Aziz \\ ${ }^{2}$ Geoinformatic Unit, \\ Geography Section, School of Humanities, \\ Universiti Sains Malaysia, \\ 11800 USM, Pulau Pinang, \\ Malaysia
}

Article DOI: https://doi.org/10.36713/epra5992

\begin{abstract}
Several locations representing recreational area, tourist spots and fish landing grounds were selected in the northern coastal region of Peninsular Malaysia for L-Microplastic (L-MP) data collection. Marine litter samples were collected during $H W S$ and LWN tidal regime. Quadrats of $50 \mathrm{~cm} x 50 \mathrm{~cm}$ were used to collect sediment from surface to $5 \mathrm{~cm}$ depth for microplastic analyses. A comparison between macroplastic and L-MP showed a significant relationship with $R^{2}=0.9579$ where linear regression computed resulted in $y=26.388 x+0.051$, where $y$ : microplastic $\left(\mathrm{kg} / \mathrm{m}^{3}\right)$ while $x$ : macroplastic $\left(\mathrm{kg} / \mathrm{m}^{3}\right)$ for Perlis sampling region. The linear regression obtained for Penang island is $y=$ $0.1248 x+0.0854$ with $R^{2}=0.9036$. Both results showed a significant difference where computed P-values were both $<0.05$. Findings from Penang island region demonstrated possibility of macroplastic and L-MP abundance relating to tidal condition, where during neap tides more plastics are settled on the beach zone as opposed to during spring tides mainly because of the difference in water volume and movement dynamics. Largest marine litter composition was plastic, followed by fabric and rubber. Although recent plastics used are of biodegradable grades meaning it breaks down into smaller sizes through exposure to sun, hydrolysis and microorganism reactions over time, these L-MP might further degrade to nanoplastic in size. The smallest microparticle reportedly detected in the oceans at the present is $1.6 \mu \mathrm{m}$ in diameter. Further breakdown of microplastics is imminent and will be difficult to detect as these nano-sized plastics enter the food chain resulting in health risks. Based on this, the UN-SDGs directly affected will be SDGs 3, 6, 12, 14 and 15.
\end{abstract}

KEYWORDS: microplastic, plastic, marine litter, marine debris, health risk, biodegradable 


\section{INTRODUCTION}

Addressing land-based pollution is now a significant and critical issue especially as global population is escalating. Since there is an unceasing growth in the amount of solid waste ending up in the environment and the lackadaisical rate of degradation of most products once in the ocean, this contributes to a steady increase in marine litter found at the coastal and marine environment. It has become an economic, environmental, human health, and aesthetic problem raising a dynamic and multidimensional challenge. Hence, marine plastic litter has become a priority issue. According to Lindeque (2017), the effect of larger plastic debris on aquatic life is well documented. However, microplastic litter has become more noticeable in recent years that may pose equal threat to marine life and human health is not well document either due to lack of research (Jahnke et al., 2017) or lack of awareness to the potential problem itself.

Laura Parker reported in National Geographic (2019) that increasing disposable plastic production has overwhelmed the world's ability to deal with them, and that plastic trash is now regarded as ubiquitous. Microplastics have been found everywhere around the world - from the highest point in Mount Everest to the lowest in the Mariana Trench. This tells us that microplastics on land are light enough to travel via the atmosphere and easily distributed within the water column since it is difficult to trace with the naked eye in the ocean. This scenario had prompted efforts for a global treaty on plastics negotiated by the United Nations.

Approximately 8.3 billion tons of plastics have been produced worldwide since the 1950s. A typical plastic waste dump is shown in Fig. 1 and not all plastic from this dump is recyclable. The continuously increasing annual plastic production since the 1950 s to 2015 and its accumulative statistics is shown in Fig. 2(a) and (b). Although in some parts of the world using plastic is illegal, the current lifestyles do not totally free us from using these materials which include computer keyboards, mouse, credit cards, air conditioning housing, parts of cameras, and even clothing items. As much as $80 \%$ of land-based waste go to the sea and $73 \%$ of beach litter is plastic. It is only between $1985-$ 1990 that plastic is recycled. In Geyer et al. (2017), global plastic waste by disposal in 2015 showed that only $20 \%$ of plastic waste is recycled, $25 \%$ is incinerated while the remaining $55 \%$ is simply discarded (Fig. 3). It is this portion that 10,000s to 100,000 s tonnes of plastic will eventually play a major role in entering the ocean to pollute it (Fig. 4).

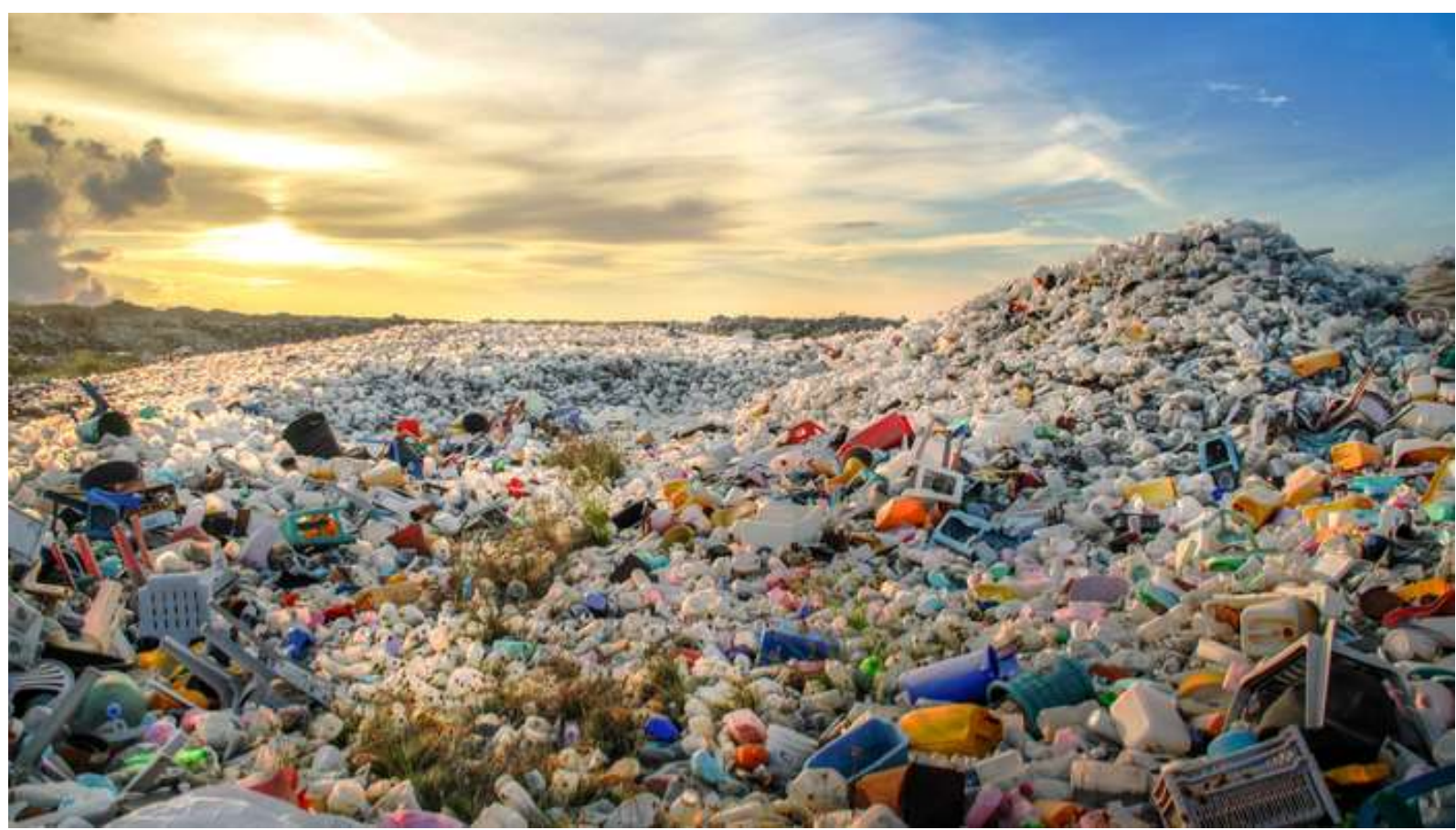

Fig. 1. Plastic waste dump. (Source: https://cdn.givingcompass.org/wpcontent/uploads/2018/10/04155651/10-Facts-About-Plastic-Pollution-You-Absolutely-Need-toKnow.jpg) 


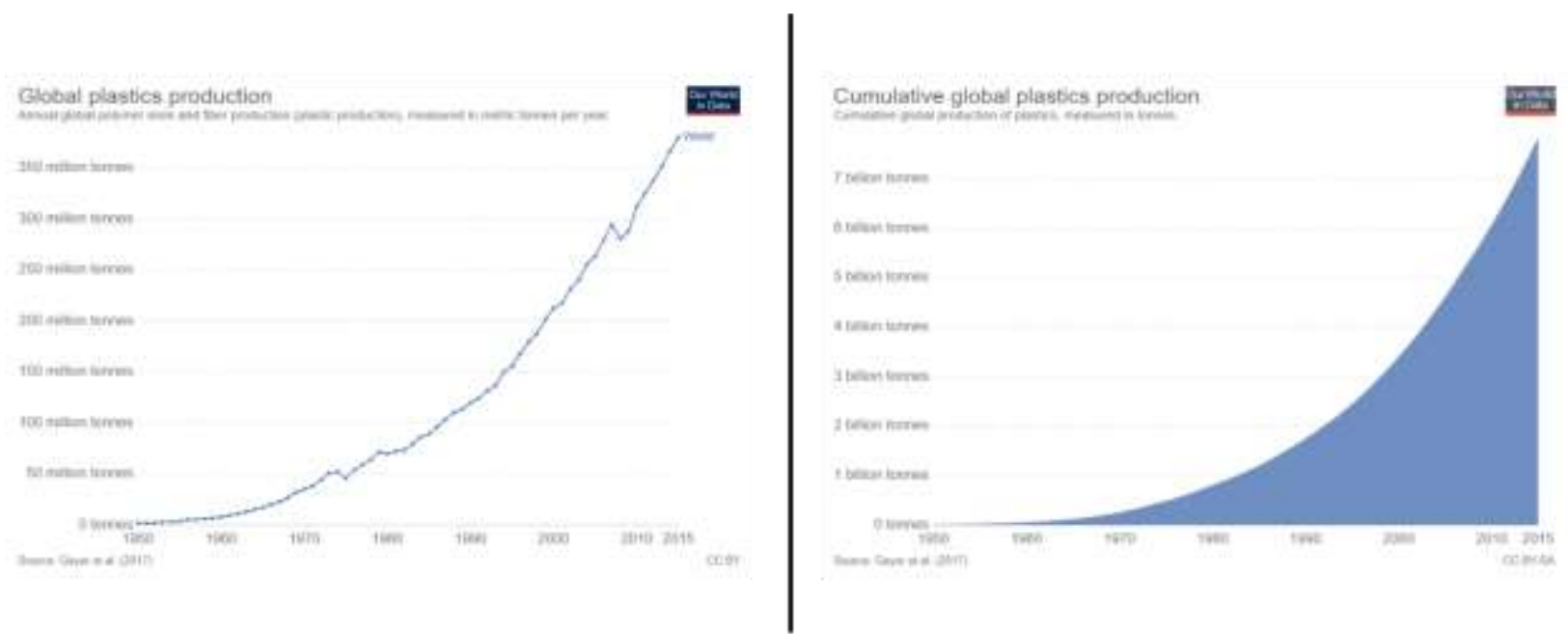

Fig 2. (a) Annual Global Plastic Production, and (b)Cumulative Global Plastic Production, between 1950 - 2015 (Source: Geyer et al., 2017)

\section{Global plastic waste by disposal}

Estimated shiare of global plastic waste by disposal method

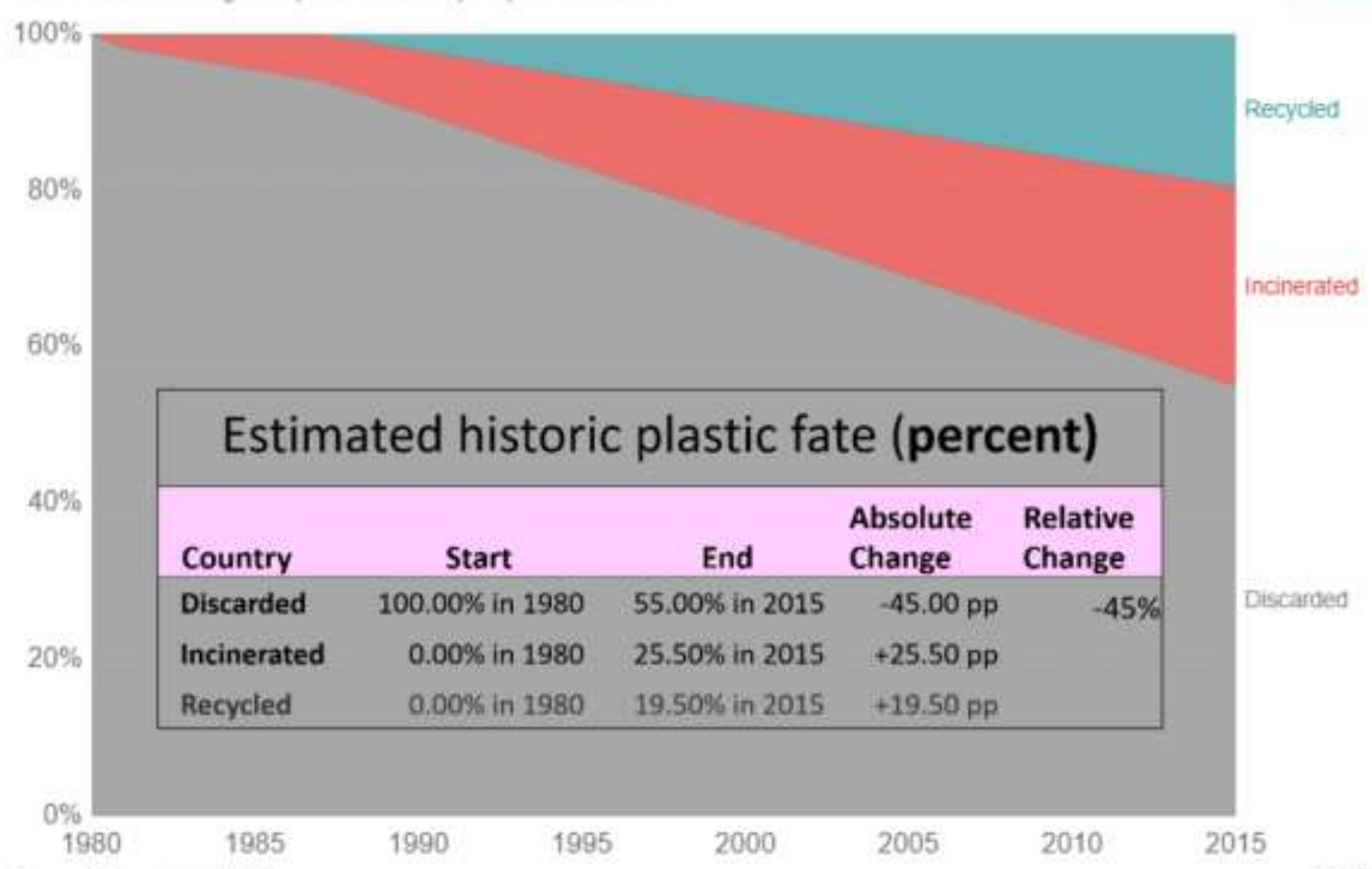

Source: Geyer et at: (2017)

Fig. 3. Disposal of global plastic waste.

(Source: Geyer et al., 2017 in https://ourworldindata.org/plastic-pollution) 


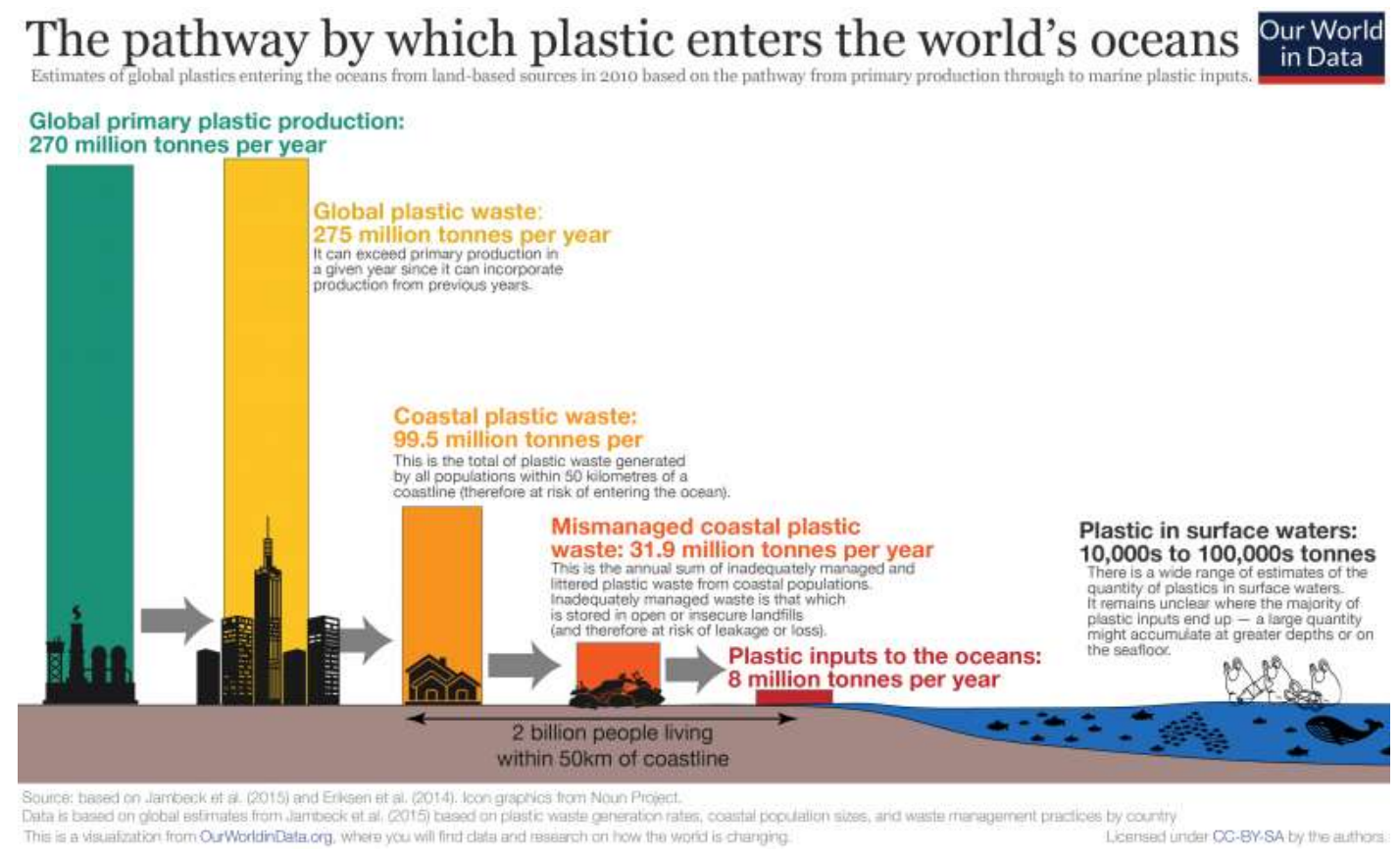

Fig. 4. Pathway of plastic entry to the world's oceans.

(Source: https://ourworldindata.org/plastic-pollution\#impacts-on-wildlife)

Plastic particles are typically grouped into categories depending on their size (as measured by their diameter) (Table 1). The most essential part of plastic pollution is plastic cannot degrade naturally but breaks into tinier sizes (hence, microplastics) over time which then resulted in multiplications of their abundance and finally interfered with the food chains in coastal ecosystems, bioaccumulated in organisms consuming these microplastics and lead to health issues in human. In addition, plastic litter pollution also impedes and degrades the aesthetic value and sustainability of an area

Table 1. Plastic size categories and diameter range.

\begin{tabular}{|c|c|}
\hline Particle category & $\begin{array}{c}\text { Diameter range } \\
\text { (mm = millimetres) }\end{array}$ \\
\hline Nanoplastics & $<0.0001 \mathrm{~mm}(0.1 \mu \mathrm{m})$ \\
\hline Small microplastics & $0.00001-1 \mathrm{~mm}$ \\
\hline Large microplastics & $1-4.75 \mathrm{~mm}$ \\
\hline Mesoplastics & $4.76-200 \mathrm{~mm}$ \\
\hline Macroplastics & $>200 \mathrm{~mm}$ \\
\hline
\end{tabular}

\section{(Source: Eriksen et al., 2014)}

Research on marine litter issues is not widely conducted in Malaysia although it appears to be a major problem in the country. Some of related studies are found to be inadequate to illustrate the level of marine pollution within the Malaysian coast. This study aimed at investigating the occurrence of macroplastic and large microplastic (L-MP) within selected locations on the northern coast of west Peninsular Malaysia. The relationship between macro- and L-MP will also be determined. This study was conducted with the hypothesis that areas with higher socio-economic activity and/or larger population will have higher macroplastic abundance. It is also expected to have higher L-MP abundance.

\section{MATERIALS AND METHODS}

\section{Study Area}

Two study sites were selected for this study, Perlis in the northern most of west coast Peninsular Malaysia and Penang island on further south (Fig. 5). Seven (7) sampling locations were identified where 4 were in Perlis and 3 in Penang island.

(1) PERLIS: Stations A, B and C are located at the vicinity of Kuala Perlis jetty where a fishing village is located. It is also an entryway for local and tourists enroute to Pulau Langkawi, a major tourism location. The fourth is Station D located further south at Kurung Tegar, a non-touristic area.

(2) PENANG: Three (3) sampling locations referred to as Stations 1,2 and 3 were identified. Station 1 is Pantai Miami 
representing one of the many famous tourist areas, Station 2 is Pantai Teluk Bahang - a traditional fish landing point, and Station 3 is Pantai Pasir Panjang which is known for its natural surrounding. Both Stations 1 and 2 are located on northern coast of Penang island, while Station 3 is at the southwest.

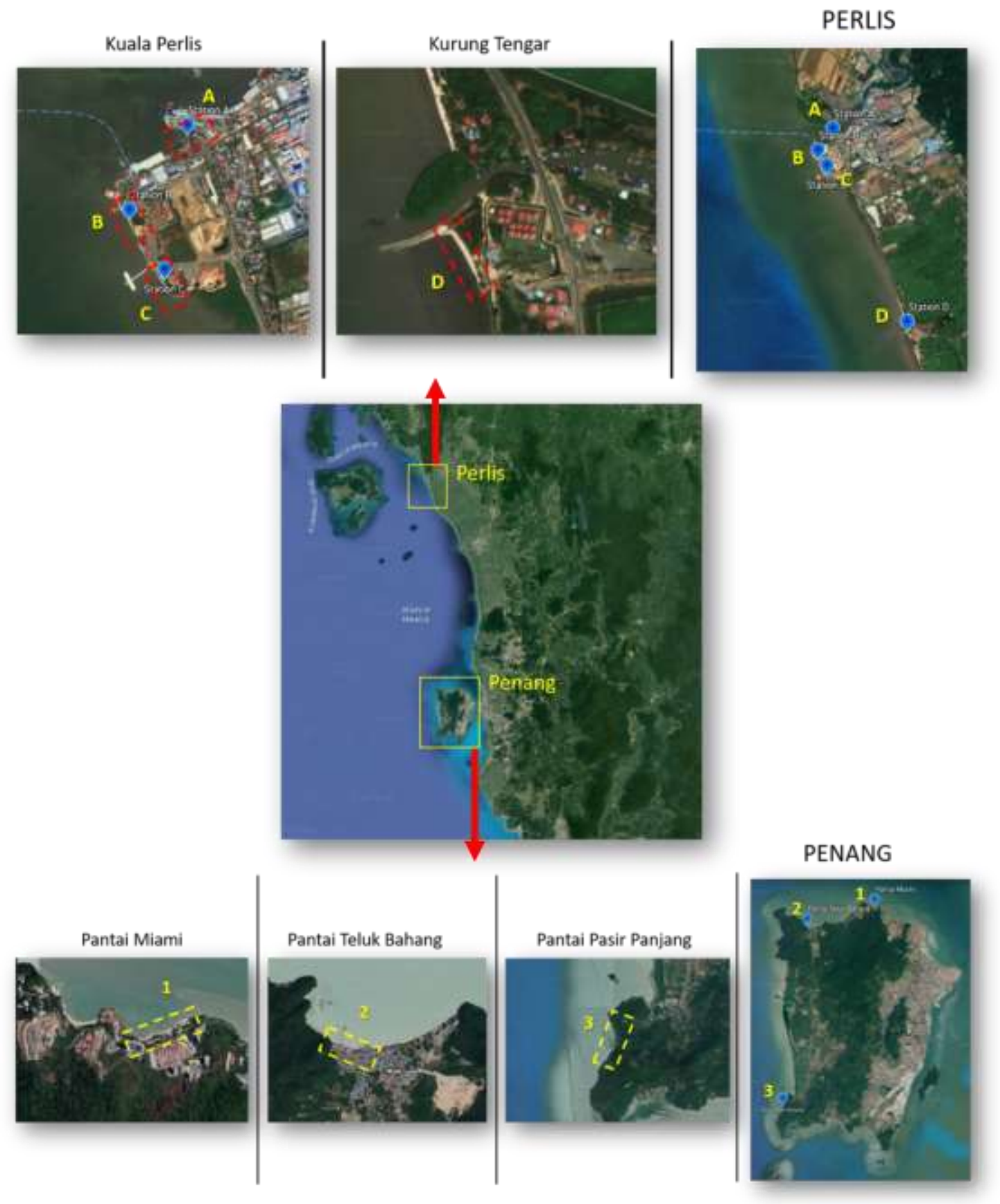

Fig. 5. Locations of sampling points in Perlis and Penang island.

(Source: base map from Google Earth)

\section{Sampling Procedure}

Sampling procedure conducted in this study was established and modified based on the field guide published by National Oceanic and Atmospheric Administration (Lippiatt et al., 2013; Opfer et al., 2012). Each sampling transect is $100 \mathrm{~m}$ and samples were taken at $10 \mathrm{~m}$ intervals along the transect using a quadrat of $50 \mathrm{~cm} \times 50 \mathrm{~cm}$. Sediment samples collected at $5 \mathrm{~cm}$ depth and sieved through $1 \mathrm{~mm}$ Endecott sieve to collect L-MP (meso- and microplastics). Microplastic particles smaller than 1 $\mathrm{mm}$ is not considered in this study. A graphic representation of L-MP sample collection is shown on Fig. 6. 


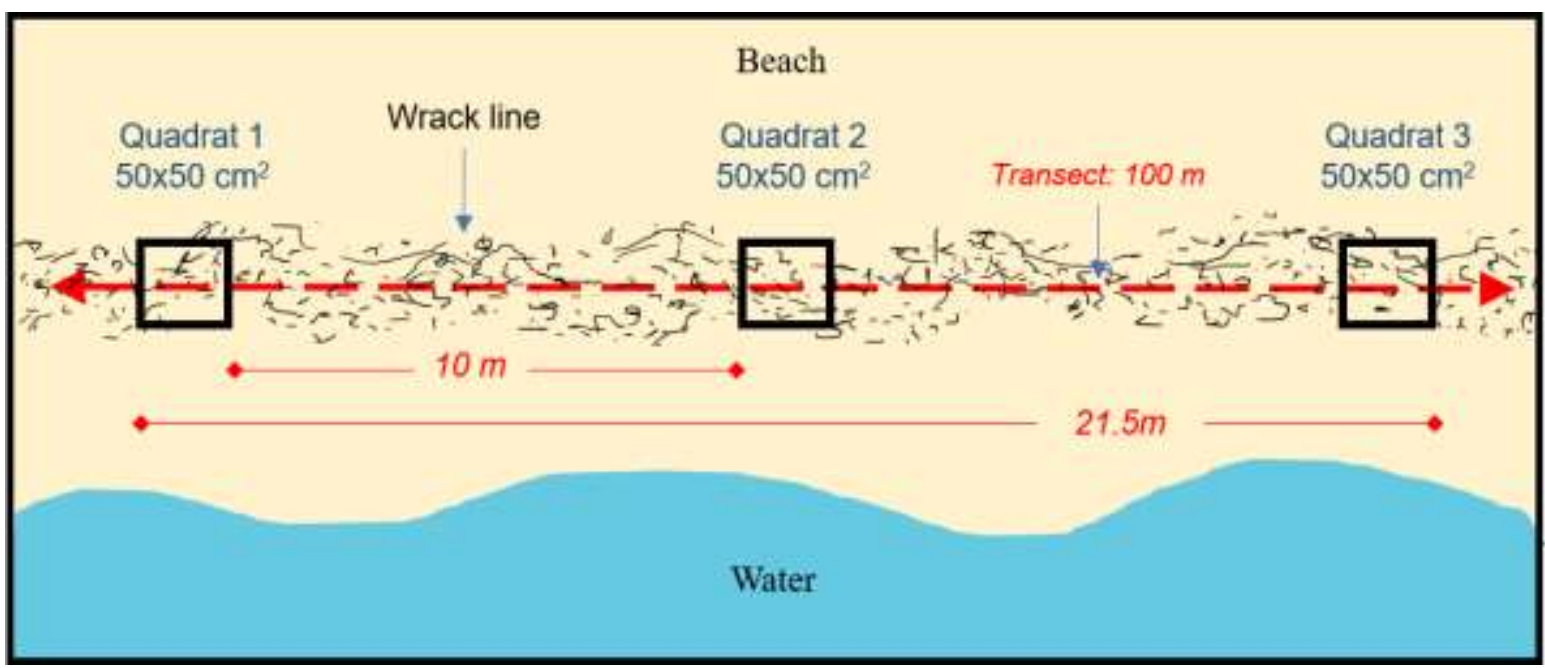

Fig. 6. Graphic representation of L-MP sample collection for this study. (Source: adapted from Tham, 2019)

Isolated L-MP particles were then categorized respectively according to their morphology which are fibre, film, pellet, foam, and fragment (GESAMP, 2019). To do this, samples collected were visually examined and sorted with the aid of an optical microscope. Hot needle test is applied (De Witte et al., 2014). The abundance of the L-MP was calculated in items $/ \mathrm{m}^{3}$ based on the formula provided by IOC-WESTPAC (2017) as below.

For macroplastics:

Sampling area $\left(\mathrm{m}^{2}\right)=$ length of transect

line $x$ width of sampling area

Abundance of macroplastic per unit area (items $/ \mathrm{m}^{2}$ or weight $/ \mathrm{m}^{2}$ ) $=$ number or weight of macroplastic $\div$ sampling area

For L-MP (meso- and microplastics):

Sampling volume $\left(\mathrm{m}^{3}\right)=$ sampling area

$\times$ sampling depth $\times$ number of quadrats

Abundance of microplastic per unit volume (items $/ \mathrm{m}^{3}$ or or weight $\left./ \mathrm{m}^{3}\right)=$ number or weight of microplastic :sampling volume

Statistical analysis is carried out to determine the possibility of significant correlation between macroplastic abundance and microplastic amount in the sediment layer using Linear Regression in the SPSS software.

\section{RESULTS AND DISCUSSION Relationship between Macroplastic and L-Microplastic in Perlis}

Results of marine litter collected from Perlis sampling region showed that most litter are from macroplastic, followed by fabric, glass, and rubber. Macroplastic from packaging dominated this category. No metal or wood were found. Results of marine litter from all 4 stations in the Perlis region is given in Fig. 7. Most macroplastic are found in Station $\mathrm{C}$ where the eateries are located. Station $\mathrm{C}$ is also nearby Stations A which is the jetty, and Station $\mathrm{B}$ which is a place of worship. The jetty area (Station A) ranked second in terms of macroplastic abundance, while Station D, representing residential area located further away, ranked third. The lowest macroplastic abundance amongst these four stations would be at the vicinity of worship. The L-MP results is shown in Fig. 8. Similarly, Station $\mathrm{C}$ has the highest L-MP abundance, followed by Station A. The residential area (Station D), however, has a lower LMP abundance compared to Station B. Results obtained in general reflected the assumption that areas having higher socio-economic activity and/or larger population tend to have higher macroplastic abundance. 


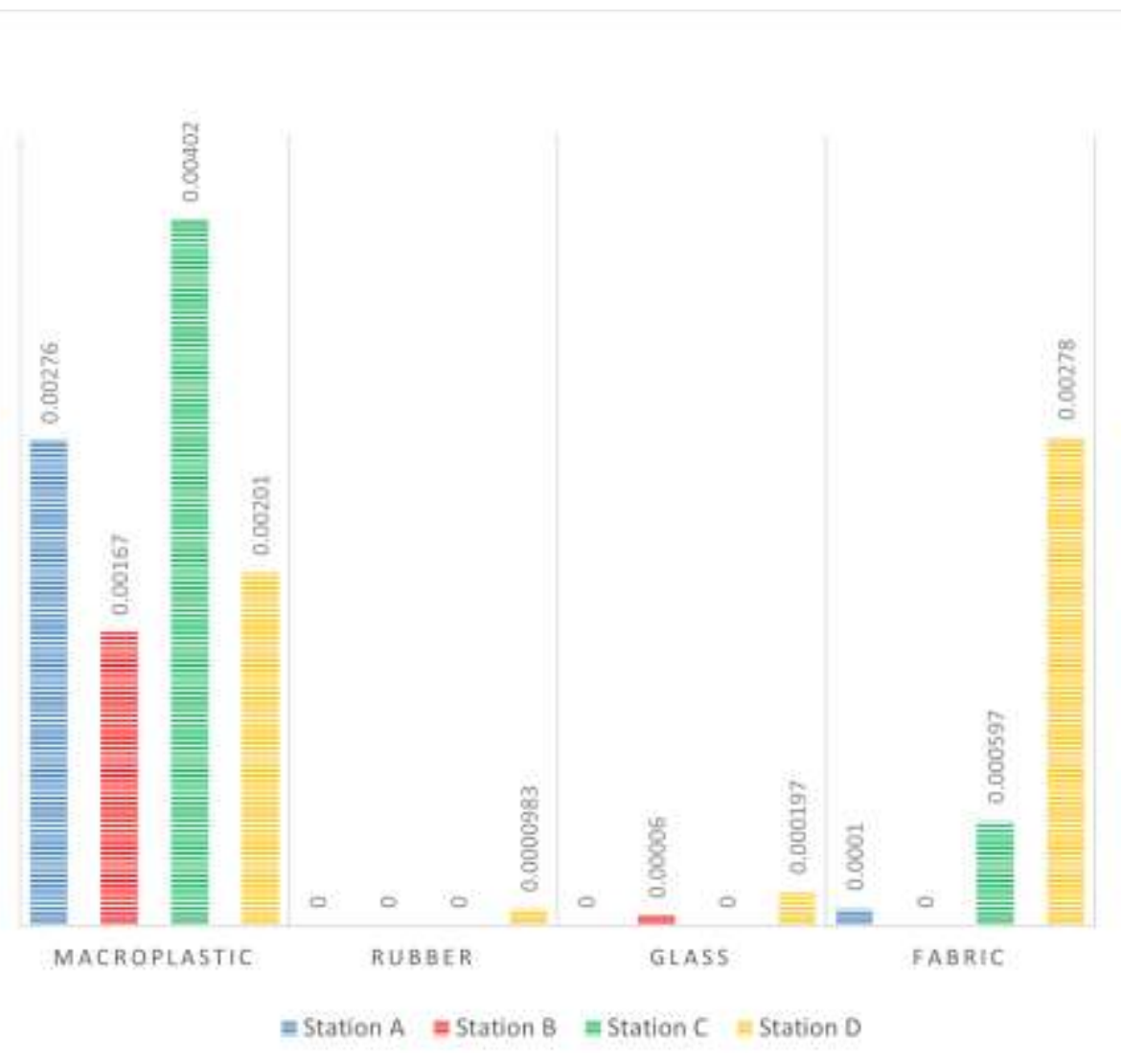

Fig. 7. Categories of marine litter collected from samples in Perlis sampling region. (Source: adapted from Zaity et al., 2020)

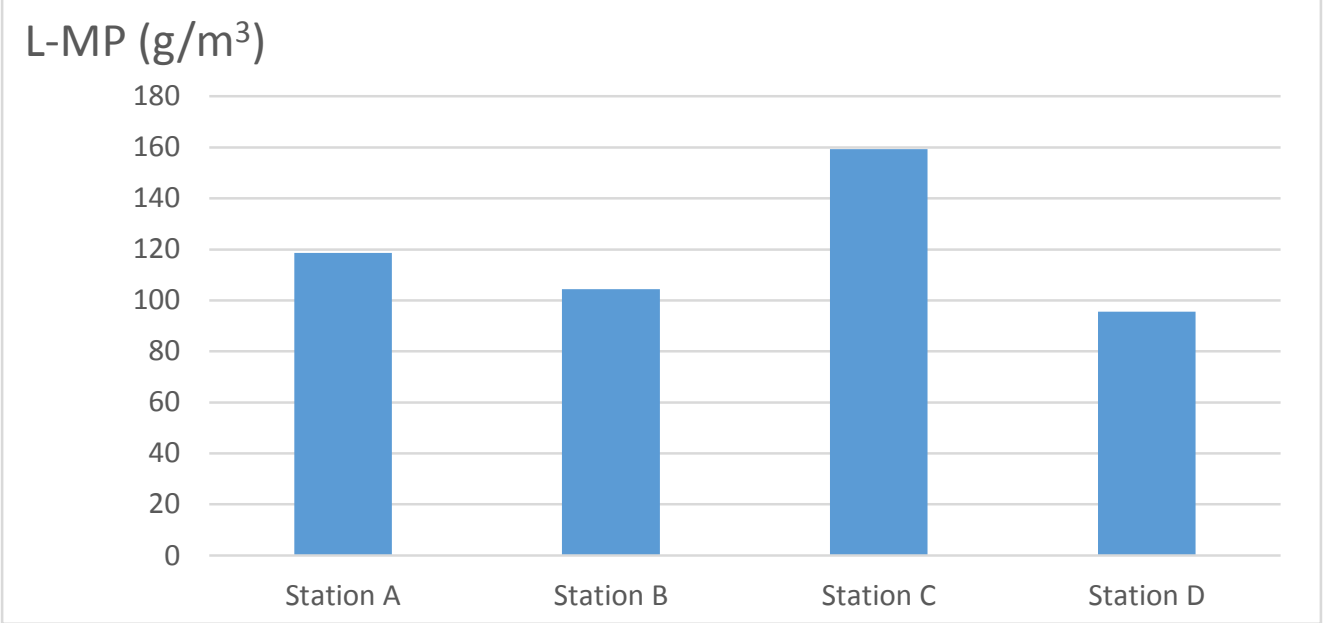

Fig. 8. Abundance of $\mathrm{L}-\mathrm{microplastic}\left(\mathrm{g} / \mathrm{m}^{3}\right)$ collected from Perlis sampling region. (Source: Zaity et al., 2020)

Based on statistical analysis, results showed a strong correlation between the amount of macroplastic litter on the beach and the abundance of microplastic in the sediment in this study (Zaity et al., 2020). Computed value of $\mathrm{R}^{2}$ is 0.9328 and this means high amount of macroplastic litter on the beach will lead to the high amount of microplastic in the sediment layer. This significant relationship is shown in Fig. 9. Regression analysis equation showed the relationship between macroplastic and microplastic as:

$$
y=26.388 x+0.051
$$

where, $\quad y=$ microplastic $\left(\mathrm{g} / \mathrm{m}^{3}\right)$, and $x=$ macroplastic $\left(\mathrm{kg} / \mathrm{m}^{2}\right)$ 


\section{Macroplastic vs Microplastic (Perlis)}

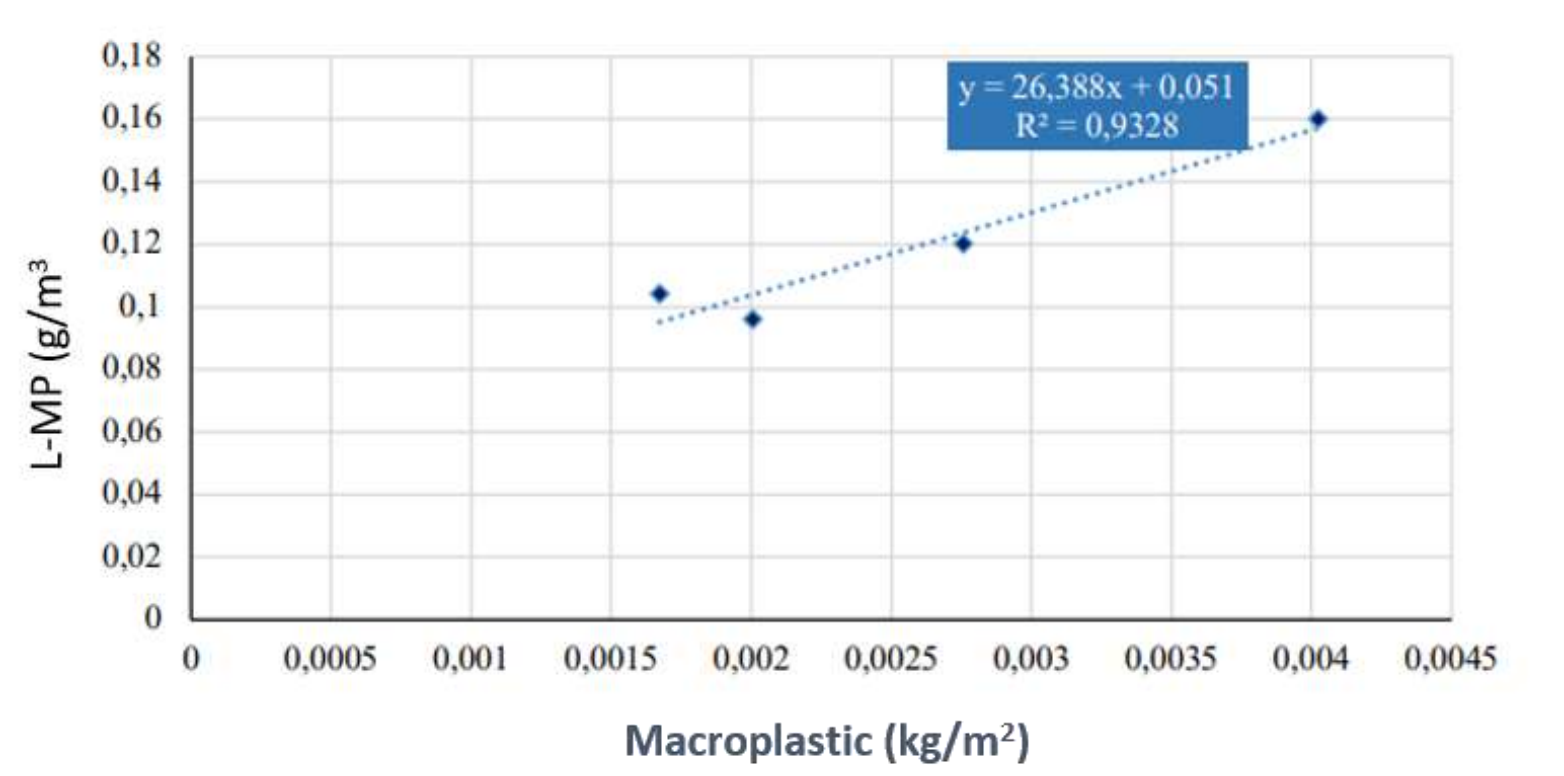

Fig. 9. The Regression relationship between macroplastic and L-Microplastic in Perlis. (Source: Zaity et al., 2020)

Summary of regression analysis between macroplastic and L-MP for Perlis is given in Table 2. Regression analysis shows adjusted $\mathrm{R}$ squared is -2 while for ANOVA result shows the total of $d f$ is 6 and $S S$ is 0.002432 . The probability output of L-MP is $0.12 \mathrm{~g} / \mathrm{m}^{3}$ in percentile 50 . The $P$-value is 0.003 $(\mathrm{p}<0.05)$, therefore this test is significantly different.
Table 2. Results of Perlis macroplastic and LMicroplastic statistical analysis for regression (a) Regression Statistic, (b) ANOVA, (c) Macroplastic Intercept, (d) Residual Output and (e) Probability Output 
(a)

\begin{tabular}{|c|c|}
\hline \multicolumn{2}{|c|}{ Regression Statistic } \\
\hline Multiple R & 0.9658293 \\
\hline R Square & 0.93282624 \\
\hline Adjusted R Square & -2 \\
\hline Standard Error & 0.00903788 \\
\hline Observations & 1 \\
\hline
\end{tabular}

(b)

\begin{tabular}{|c|c|c|c|c|c|}
\hline ANOVA & $d f$ & SS & MS & $F$ & Significance $F$ \\
\hline Regression & 4 & 0.00226863 & 0.000567158 & 27.7735303 & \#NUM! \\
\hline Residual & 2 & 0.00016337 & $8.16833 \mathrm{E}-05$ & & \\
\hline Total & 6 & 0.002432 & & & \\
\hline
\end{tabular}

(c)

\begin{tabular}{|c|c|c|c|c|c|c|c|c|}
\hline & $\begin{array}{c}\text { Coofficient } \\
\frac{5}{5}\end{array}$ & $\begin{array}{l}\text { Standarad } \\
\text { Errar }\end{array}$ & ${ }_{t \text { Strat }}$ & P-nufue & Lower 95\% & Upper $95 \%$ & $\begin{array}{l}\text { Lowner } \\
95.0 \% 6\end{array}$ & $\begin{array}{l}\text { Upper } \\
\text { 95.0\%\% }\end{array}$ \\
\hline \multirow{2}{*}{$\begin{array}{c}\text { Intercept } \\
\text { Macroplasti } \\
c \\
\left(\mathrm{~kg} / \mathrm{m}^{2}\right)\end{array}$} & & & & & & & $\begin{array}{c}-4.4042 \mathrm{E}- \\
306\end{array}$ & $\begin{array}{c}4.4043 \mathrm{E}= \\
306\end{array}$ \\
\hline & & & & & & $\begin{array}{c}13404 \mathrm{E} . \\
306\end{array}$ & $\begin{array}{c}\begin{array}{c}13404 \mathrm{E}= \\
306\end{array} \\
\end{array}$ & \\
\hline 0.001275833 & & & & & & & 0 & 0 \\
\hline 0.00167333 & $\begin{array}{c}0.0510073 \\
1 \\
\end{array}$ & $\begin{array}{c}0.0138494 \\
3 \\
\end{array}$ & $\begin{array}{c}3.68299038 \\
6 \\
\end{array}$ & $\begin{array}{c}0.0664457 \\
4 \\
\end{array}$ & 0.00858197 & 0.1105966 & 0.00558197 & 0.1105966 \\
\hline 0.00402167 & $\begin{array}{c}26.387640 \\
5\end{array}$ & 5.00070856 & $\begin{array}{c}5.27005979 \\
6 \\
\end{array}$ & 0.0341707 & $\begin{array}{c}4.84388999 \\
1 \\
\end{array}$ & $\begin{array}{c}47.9313910 \\
3 \\
\end{array}$ & $\begin{array}{c}4.84388999 \\
1 \\
\end{array}$ & $\begin{array}{c}47.9313910 \\
3 \\
\end{array}$ \\
\hline 0.0020015 & & & & & & & & \\
\hline
\end{tabular}

(d)

\begin{tabular}{|c|c|c|}
\hline \multicolumn{3}{|c|}{ Residual Output } \\
\hline Observation & $\begin{array}{c}\text { Predicted Microplastic } \\
\left(\mathrm{kg} / \mathrm{m}^{3}\right)\end{array}$ & Residuals \\
\hline 1 & 729969.053 & -729968.933 \\
\hline
\end{tabular}

(e)

\begin{tabular}{|c|c|}
\hline \multicolumn{2}{|c|}{ Probability Output } \\
\hline 50 & 0.12 \\
\hline Percentile & Microplastic $\left(\mathrm{kg} / \mathrm{m}^{3}\right)$ \\
\hline
\end{tabular}

(Source: Zaity et al., 2020)

\section{Relationship between macroplastic and L-Microplastic in Penang island}

For Penang island, dominant macroplastic category was also from packaging. All sampling locations contained mostly disposable water bottles. Results of macroplastic collected from Penang island is given in Fig. 10. Data collected during spring tidal condition samplings showed a much lower abundance of macroplastic compared to during neap tidal condition. One probable explanation to this is due to the difference in the dynamics of water volume movement - during spring higher volume movement is involved while the opposite is observed during neap. Thus, during neap, more macroplastic will settle on the beach front. Higher abundance of macroplastic is also observed at locations with higher socio-economic activity which are Pantai Teluk Bahang (fish landing point) and Pantai Miami (a tourist recreational point). Pantai Pasir Panjang had showed much lower macroplastic abundance probably because this location is rather secluded, more pristine, not crowded and is surrounded by forest. 


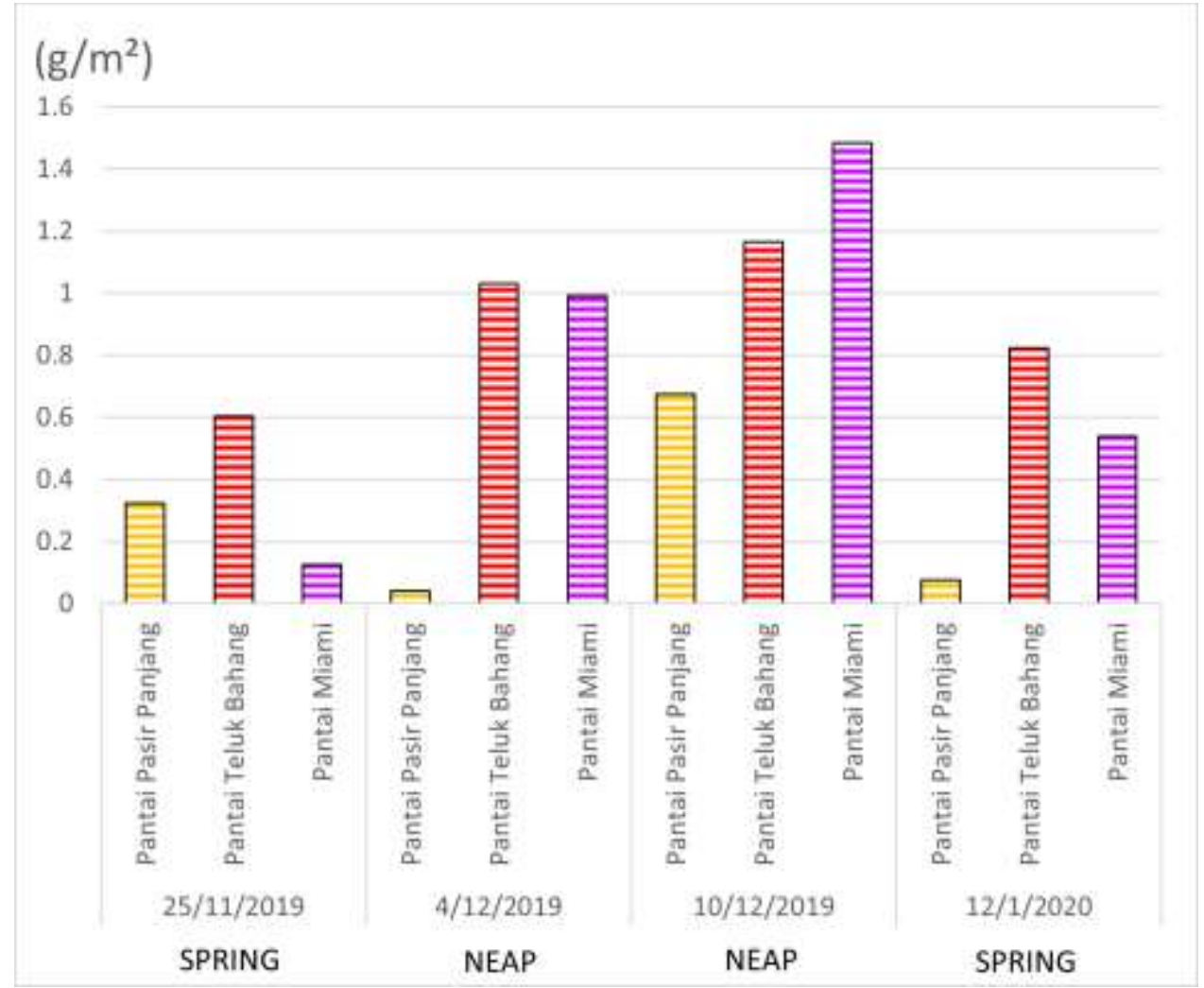

Fig. 10. Macroplastic abundance in Penang island region.

Fig. 11 shows L-MP collected from sediment samples in Penang island sampling region. From the chart, it is obvious more L-MP were also found in all sampling stations during neap tidal condition. Unlike macroplastic abundance profile shown in Fig. 10, LMP was not detected in Pantai Pasir Panjang during spring tidal sampling on 25 November 2019 and 12
January 2020. None was found too in the samples taken from Pantai Miami on 25 November 2019.Perhaps another intensive sampling is necessary to ascertain the reason for this. However, Pantai Teluk Bahang has consistently showed high abundance of macroplastic and L-MP in this study.

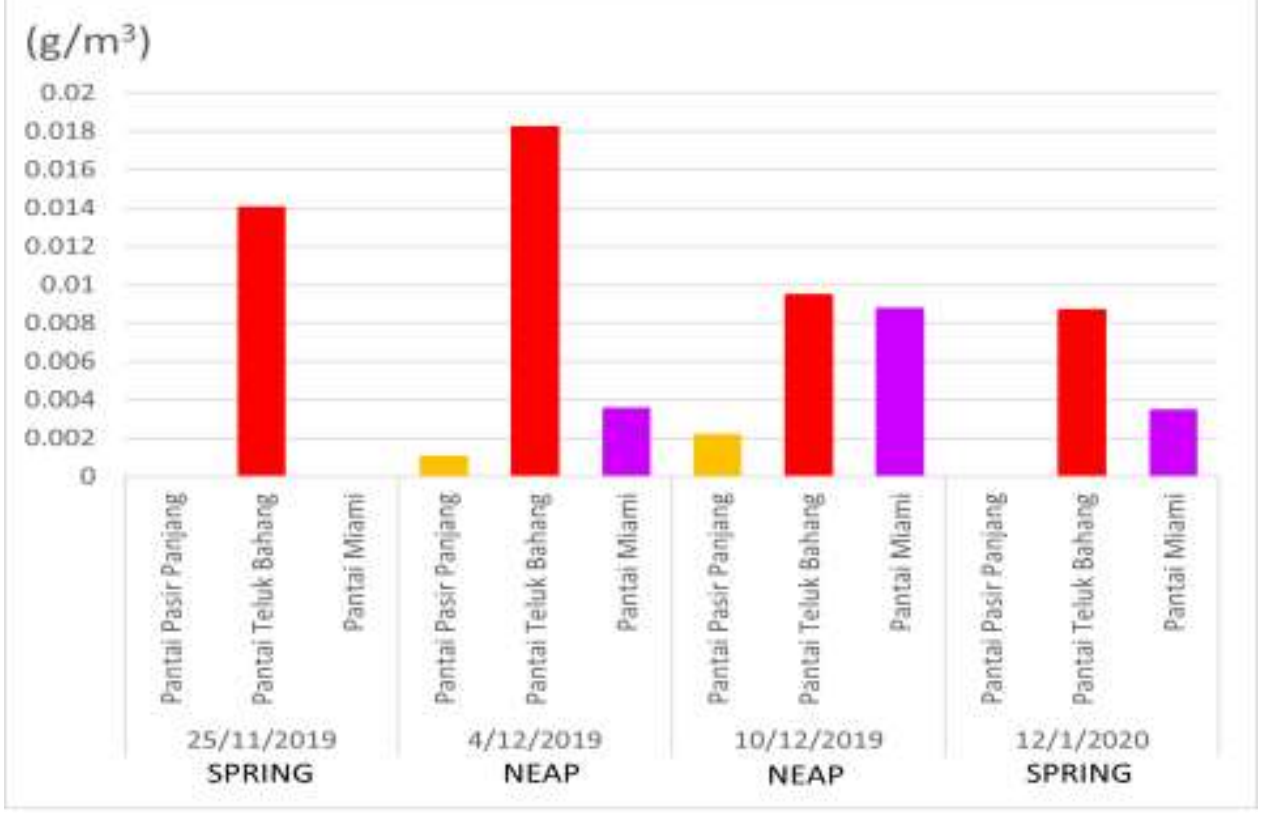

Fig. 11. L-Microplastic abundance in Penang region. 
Similarly to analysis of Perlis data, regression analysis from Penang island data also showed a strong correlation between the amount of macroplastic litter on the beach and the abundance of L-MP in the sediment during this study period. The $\mathrm{R}^{2}$ value computed was 0.9036 indicating high abundance of macroplastic litter on the beach will lead to high abundance of L-MP in the sediment layer (Fig. 12). Linear Regression analysis equation between macroplastic and microplastic for Penang island region was computed as:

$$
y=0.1248 x+0.0854
$$

where, $\quad y=$ microplastic $\left(\mathrm{g} / \mathrm{m}^{3}\right)$, and $x=$ macroplastic $\left(\mathrm{kg} / \mathrm{m}^{2}\right)$

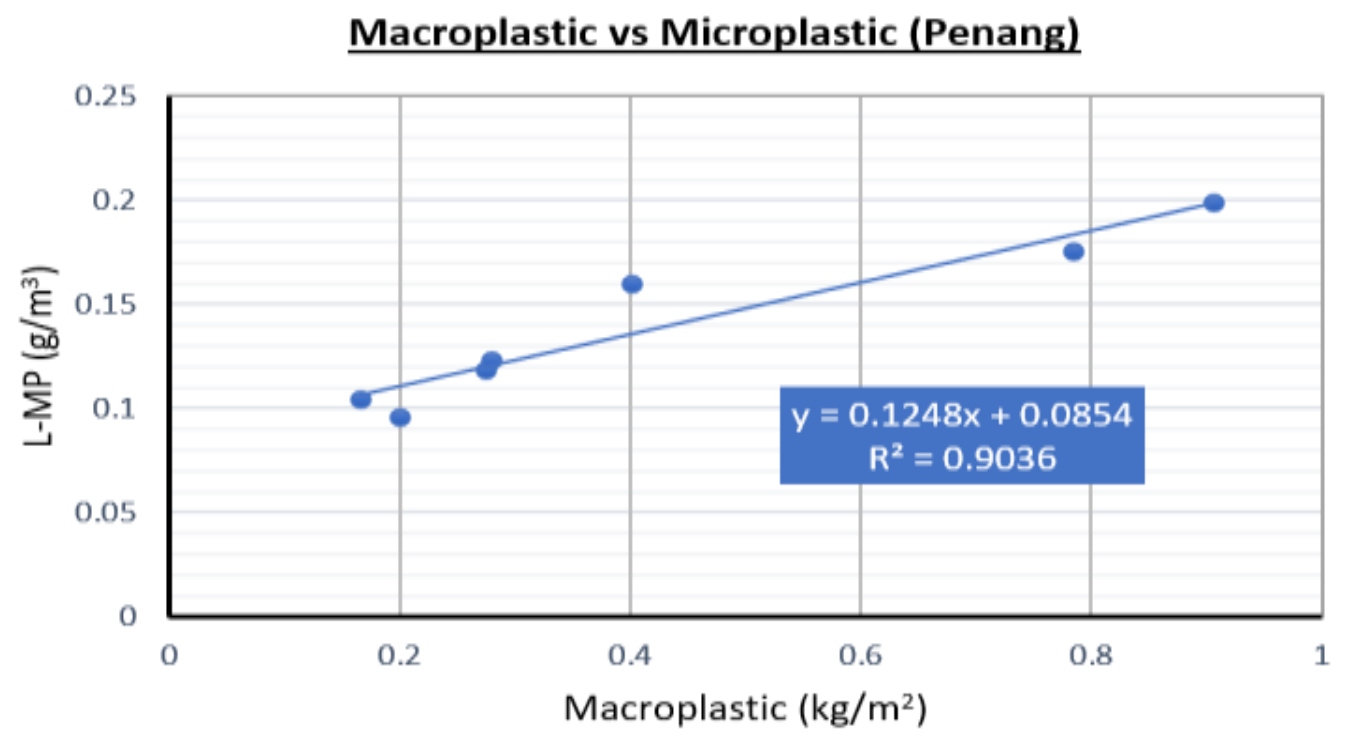

Fig. 12. The Regression relationship between macroplastic and L-Microplastic in Penang island.

Summary of regression analysis between macroplastic and L-MP for Penang island sampling region is given in Table 3 . Regression analysis shows adjusted $\mathrm{R}$ squared is 0.8843 while for ANOVA result shows the total of $d f$ is 6 and $S S$ is 0.008987 . The probability output of L-MP is 0.1233 $\mathrm{g} / \mathrm{m}^{3}$ in percentile 50 . This value is very similar to the results obtained for Perlis region $(0.12 \mathrm{~g} / \mathrm{m} 3$ in percentile 50). The $P$-value is $0.001 \quad(\mathrm{p}<0.05)$, therefore this test is significantly different.

Table 3. Results of Penang island macroplastic and L-Microplastic statistical analysis for regression (a) Regression Statistic, (b) ANOVA, (c) Macroplastic Intercept, (d) Residual Output and (e) Probability Output 
(a)

\begin{tabular}{|c|c|}
\hline \multicolumn{2}{|c|}{ Regression Statistic } \\
\hline Multiple R & 0.950555231 \\
\hline R Square & 0.903555247 \\
\hline Adiusted R Square & 0.854266296 \\
\hline Standard Error & 0.013165957 \\
\hline Observations & 7 \\
\hline
\end{tabular}

(b)

\begin{tabular}{|l|l|l|l|l|l|}
\hline ANNOVA & df & SS & MS & $F$ & Significance $F$ \\
\hline Regression & 1 & 0.00812 & 0.008119905 & 46.84315209 & 0.001016607 \\
\hline Residual & 5 & 0.000867 & 0.000173342 & & \\
\hline Total & 6 & 0.008987 & & & \\
\hline
\end{tabular}

(c)

\begin{tabular}{|l|c|c|c|c|c|c|c|c|}
\hline & Coefficient 2 & $\begin{array}{c}\text { Standayd } \\
\text { errer }\end{array}$ & TStat & P-value & Lower 95\% & Upper 95\% & Lower 95\% & Upper 95\% \\
\hline $\begin{array}{l}\text { Intercept } \\
\begin{array}{l}\text { Macroplastic } \\
\left(\mathrm{kg} / \mathrm{m}^{2}\right)\end{array}\end{array}$ & 0.08544699 & 0.009303 & 9.18499613 & 0.00025661 & 0.06153315 & 0.10936083 & 0.06153316 & 0.10936083 \\
\hline $\mathrm{X}$ Variable 1 & 0.124816387 & 0.018237 & 6.844205731 & 0.001016607 & 0.077937209 & 0.171695564 & 0.077937209 & 0.171695564 \\
\hline
\end{tabular}

(d)

\begin{tabular}{|c|c|c|}
\hline \multicolumn{2}{|c|}{ Residual Output } \\
\hline Observation & Predicted L-Microplastic $\left(\mathrm{g} / \mathrm{m}^{3}\right)$ & Residuals \\
\hline 1 & 0.119896317 & -0.0013 \\
\hline 2 & 0.106291331 & -0.00189 \\
\hline 3 & 0.135623182 & 0.023677 \\
\hline 4 & 0.110535088 & -0.01494 \\
\hline 5 & 0.183427858 & -0.00833 \\
\hline 6 & 0.198530641 & -0.00013 \\
\hline 7 & 0.120395383 & 0.002904 \\
\hline
\end{tabular}

(e)

\begin{tabular}{|c|c|}
\hline \multicolumn{2}{|c|}{ Probability Output } \\
\hline 50 & 0.1233 \\
\hline Percentile & L-Microplastic $\left(\mathrm{g} / \mathrm{m}^{3}\right)$ \\
\hline
\end{tabular}

Generally, data collected during this study demonstrated that the major macroplastic problem is from packaging category. This is further supported by data from Geyer et al. (2015) (Fig. 13) that the largest plastic production in the industrial sector is from packaging amounting to 1.46 million tonnes in 2015 alone. This is the production to support the 7 billion global population then, and this figure had increased since that date. 


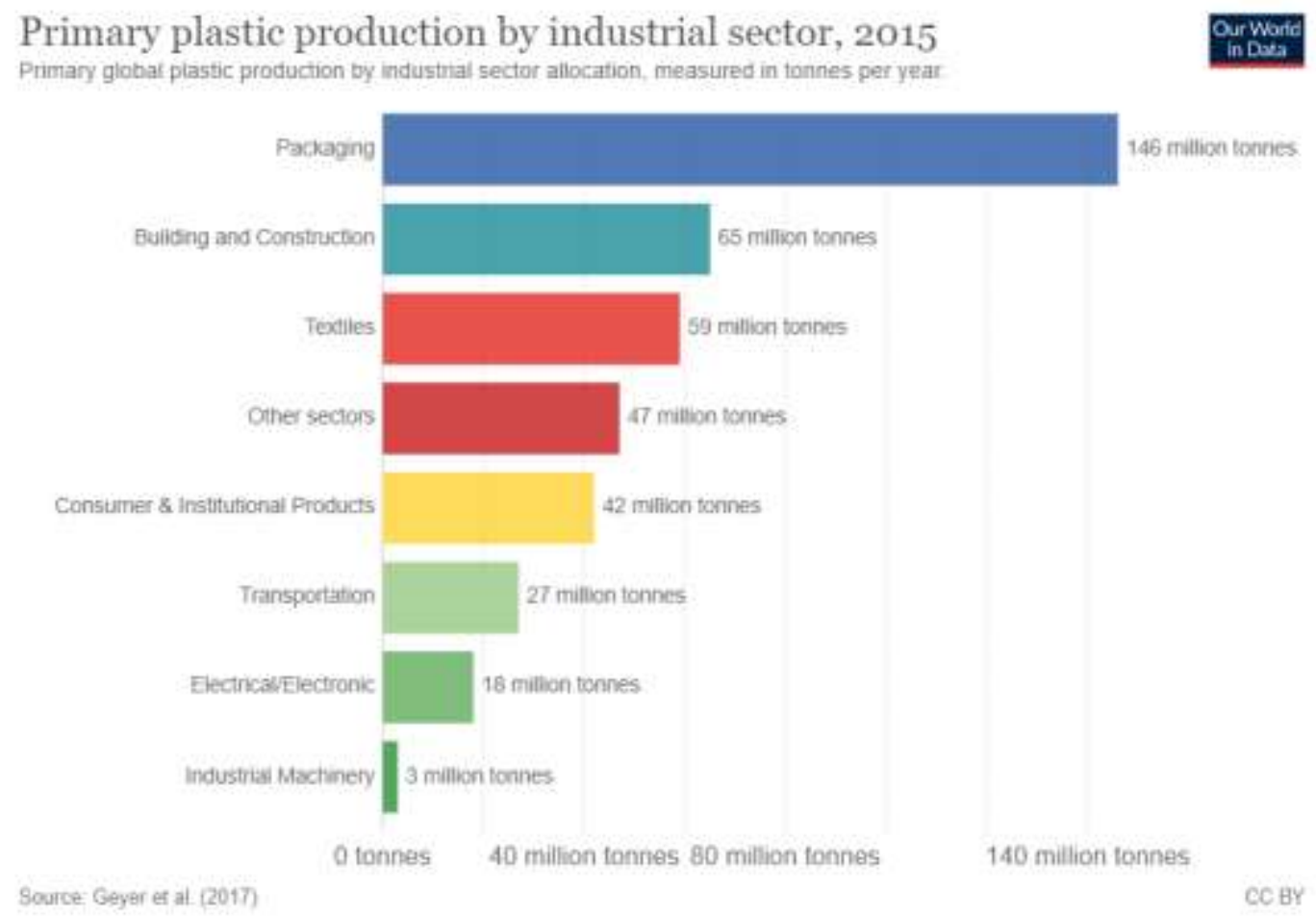

Fig. 13. Primary plastic production by industrial section, 2015.

(Source: Geyer et al., 2017 in https://ourworldindata.org/plastic-pollution)

It is imperative to study further the potential effect of microplastics in the environment. The information will be indispensable as it allows us to connect the potential consequences of these microparticles within our physical environment which will affect our wellbeing. To relate these with our desired sustainable environment and to achieve the much hard-pressed 17 goals by the United Nations (UN-SDGs), we need to observe the big picture and realize the potentials and consequences we have obsessively fed into our environment.

How most UN-SDGs are connected in macro- and microplastic pathways is graphically demonstrated in Fig. 14. Microplastics are in the environment without being noticed and are often eaten by organisms which may potentially cause harm. Microplastic particles can enter the food chain and can be found as a vector for the movement of the organism's community and chemical pollutants. Most of the deaths to animals are caused by entanglement or starvation due to macroplastics. Abandoned fishing gears, discarded six-pack rings, clear plastic bags are amongst the macroplastics causing entanglement to seals, turtles, and other marine animals. More than 100 aquatic species have been found to contain microplastics, and these species (shrimp, fish, mussels) are amongst those ending up in our food chain, our meal consumptions. Tiny microplastic particles pass through our digestive systems can either be expelled without any consequence, or it may block digestive tracts causing death. Undigested materials may stay within the stomach causing further problems. It is known that land-based animals consumed plastics which eventually caused death to some (National Geographic, 2017). There were confirmed reports of liver and cell damages, and reproductive system disruptions prompting a reduced fecundity in shell fishes. Research also show that larval fish are consuming nanofibers in the early days of their lifecycles, and this has raised very concern questions amongst researchers on the possible effects of plastics on fish populations. Bioaccumulation will result in contamination of fish. This will eventually end up in the topmost consumer in the trophic hierarchy. As mentioned, this chain of reactions will affect our efforts in achieving sustainability, particularly the UN-SDGs.

The direct effect is on SDG 3,14 and 15 as shown in Fig. 14. The indirect effect of plastic pollution, may it be macro- or microplastic will be wide and transcends almost all UN-SDGs. The relationship is intricate and complex. To solve the microplastic pollution requires a holistic approach involving inter-, multi-, and transdisciplinary perspectives where all fields involved are treated equally to address this plastic tide. 


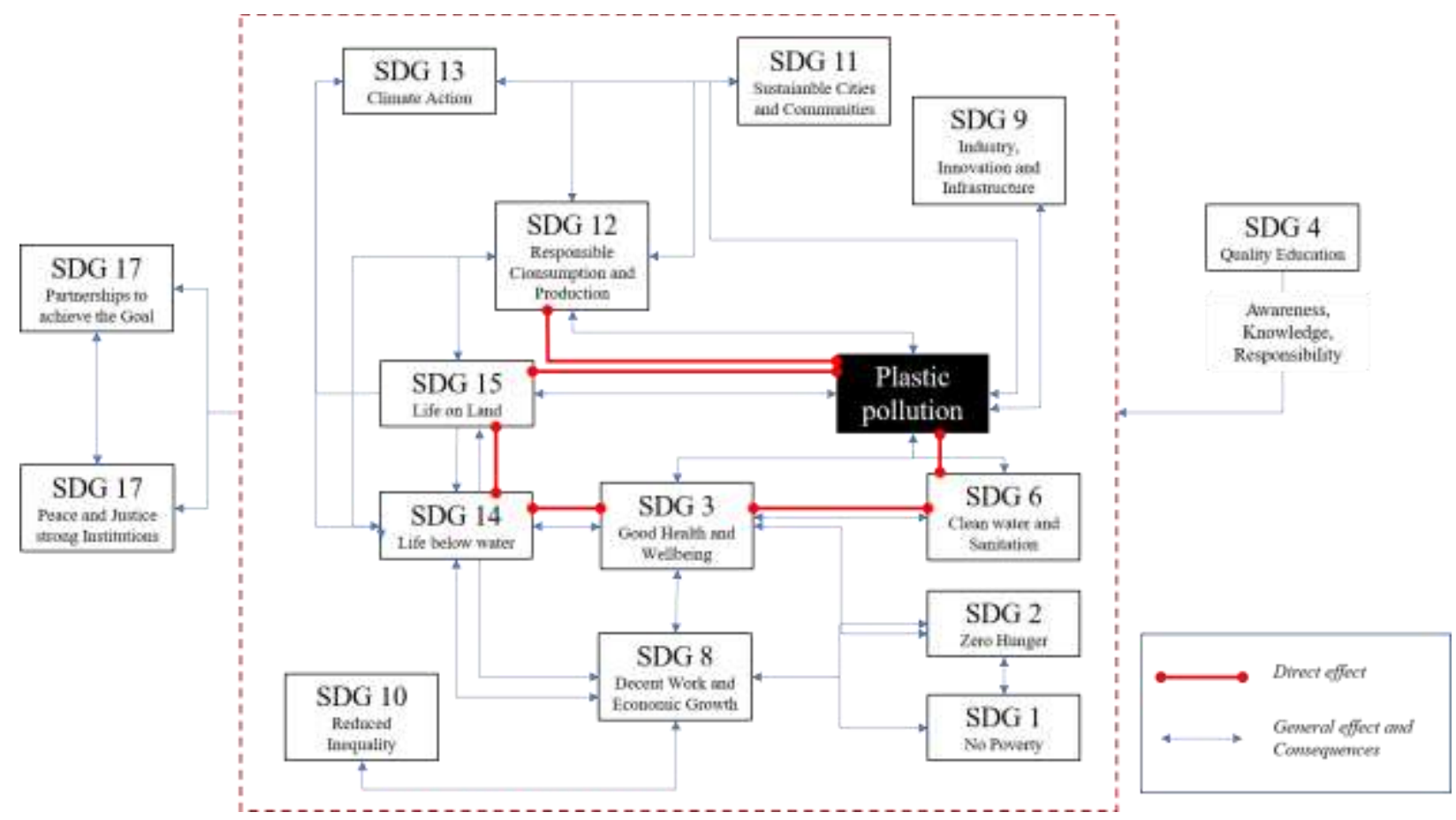

Fig. 14. Direct and direct relationships (consequences) of plastic pollution in the environment and UN-Sustainable development Goals.

\section{CONCLUSION}

The main aim of this study in investigating the occurrence of macroplastic and large microplastic (L-MP) within selected locations on the northern coast of west Peninsular Malaysia was achieved where these materials were found in abundance and that there were significant relationships between the two materials. For Perlis sampling region, the relationship between macroplastic and L-MP was computed as $\mathrm{y}=26.388 \mathrm{x}+0.051$, where $\mathrm{y}$ : microplastic $\left(\mathrm{kg} / \mathrm{m}^{3}\right)$ while $\mathrm{x}$ : macroplastic $\left(\mathrm{kg} / \mathrm{m}^{3}\right)$ with an $\mathrm{R}^{2}=0.9579$, while for Penang island sampling region, computed relationship was $y=0.1248 x+$ 0.0854 with an $\mathrm{R}^{2}=0.9036$. In this study, the hypothesis or assumption that areas with higher socio-economic activity and/or larger population will have higher macroplastic and L-MP abundance was accepted and proven. Results from both sampling regions showed significant difference where computed $P$-values were less than $\mathrm{p}-0.05(\mathrm{p}<0.05)$. Findings from Penang island region demonstrated possibility of macroplastic and L-MP abundance relating to tidal condition, where during neap tides more plastics are settled on the beach zone as opposed to during spring tides mainly because of the difference in water volume and movement dynamics. This observation will need further research to reach affirmation. The largest marine litter composition was found to be plastic, followed by fabric and rubber. No metal or wood marine litter was found in both sampling regions. Although recent plastics used are of biodegradable grades which will break down into smaller sizes through exposure to sun, hydrolysis and microorganism reactions over time, these L-MP might further degrade to nanoplastic in size. The smallest microparticle reportedly detected in the oceans at the present is $1.6 \mu \mathrm{m}$ in diameter. Further breakdown of microplastics is imminent and will be difficult to detect as these nano-sized plastics enter the food chain resulting in health risks. How these microplastics pose health risks are based on the effects and relationships that connect the UN-SDGs. The most directly affected will be SDGs 3, 6, 12, 14 and 15. The other SDGs are also affected but indirectly since plastic pollution is now seen as one of the wicked problems to be solved. This requires a holistic approach involving multiple levels of disciplinary with equal roles.

\section{Conflict of interest}

Authors declare no conflict of interest.

\section{Acknowledgements}

The authors would like to thank Universiti Sains Malaysia for supporting this project through its Bridging Incentive Grant "The Effects of Microplastics on Coastal and Marine Environment" Acc. Ref. 304 PHUMANITI 6316352

\section{REFERENCES}

1. GESAMP (Group of Experts on Scientific Aspects of Marine Protection), (2015). Sources, FateaAnd Effects of Microplastics In The 
Marine Environment: Part 2 Of A Global Assessment. International Maritime Organization b4 Albert Embankment, London SE1 7SR. www.imo.org

2. De Witte, B., Devriese L, Bekaert K, Hoffman S, Vandermeersch $G$, Cooreman K, Robbens $J$. (2014). Quality assessment of the blue mussel (Mytilus edulis): comparison between commercial and wild types. Mar Pollut Bull. 2014 Aug 15;85(1):146-55. doi: 10.1016/j.marpolbul.2014.06.006. Еpub 2014 Jun 23. PMID: 24969855.

3. Eriksen, M., Lebreton, L. C., Carson, H. S., Thiel, M., Moore, C. J., Borerro, J. C., ... \& Reisser, J. (2014). Plastic pollution in the world's oceans: more than 5 trillion plastic pieces weighing over 250,000 tons afloat at sea. PloS one, 9(12), e111913. Available at: http://journals.plos.org/plosone/article? $i d=10$ .1371/journal.pone.0111913.

4. GESAMP. (2019). Guidelines or the monitoring and assessment of plastic litter in the ocean. (Kershaw, P.J., Turra A. and Galgani F. editors), (IMO/FAO/UNESCOIOC/ UNIDO/ WMO/IAEA/UN/UNEP/UNDP. Joint Group of Experts on the Scientific Aspects of Marine Envrironmental Protection). Reports and Studies. GESAMP No. 99, 130 p.

5. Geyer, R., Jambeck, J., \& Law, K. (2017). Production, Use, and Fate of All Plastics Ever Made. Science Advances, 3(7), 25-29. e1700782

6. http://advances.sciencemag.org/content/3/7/e1 700782

7. https://cdn.givingcompass.org/wpcontent/uploads/2018/10/04155651/10-FactsAbout-Plastic-Pollution-You-Absolutely-Need-toKnow.jpg

8. https://ourworldindata.org/plastic-pollution

9. https://ourworldindata.org/plasticpollution\#impacts-on-wildlife)

10. IOC-WESTPAC (2017). Training Workshop on Distribution, Source, Fate and Impacts of Marine Microplastics in Asia and the Pacific, Phuet, Thailand, 20-22 September 2017. http://iocwestpac.org/calendar/834.html

11. Jahnke, A., Arp, H.P.H., Escher, B.I., Gewert, B., Gorokhova, E., Kühnel, D.,Ogonowski, M., Potthoff, A., Rummel, C., Schmitt-Jansen, M., Toorman, E., and MacLeod, M. (2017). Reducing uncertainty and confronting ignorance about the possible impacts of weathering plastics in the marine environment. Environmental Science \& Technology Letters 4(3): 8590. https://hdl.handle.net/10.1021/acs.estlett. 7 b0 $\underline{0008}$

12. Jambeck JR, Geyer R, Wilcox C, Siegler TR, Perryman $M$, Andrady A, Narayan $R$, Law KL.(2015). Plastic waste inputs from land into the ocean. Marine Pollution. 347(6223):768-71. doi: 10.1126/science.1260352. PMID: 25678662.

13. Lindeque, P.K., Matthew Cole, Rachel L. Coppock, Ceri N. Lewis, Rachael Z. Miller, Andrew J.R. Watts, Alice Wilson-McNeal, Stephanie L. Wright, and Tamara S. Galloway
(2017). Are we underestimating microplastic abundance in the marine environment? A comparison of microplastic capture with nets of different mesh-size. Environmental Pollution, Volume 265, Part A, 2020, 114721. https://doi.org/10.1016/j.envpol.2020.114721

14. Lippiatt, S., Opfer, S., and Arthur, C. 2013. Marine Debris Monitoring and Assessment. NOAA Technical Memorandum NOS-OR\&R-46.

15. https://www.nationalgeographic.com/environmen t/habitats/plastic-pollution/

16. National Geographic (2017). The world agrees there's a plastic waste crisis - can it agree on a solution? https://www.nationalgeographic.com/environm ent/2019/03/un-environment-plastic-pollutionnegotiations/

17. National Geographic (2019). The world's plastic pollution crisis explained. (Laura Parker).

https://www.nationalgeographic.com/environm ent/habitats/plastic-pollution/

18. NOAA, (2015). Laboratory methods for the analysis of microplastics in the marine environment: recommendations for quantifying synthetic particles in waters and sediments. National Oceanic and Atmospheric Administration; U.S. Department of Commerce; Technical Memorandum NOS-OR\&R-48.

19. Opfer, S., Arthur, C., and Lippiatt, S. (2012). NOAA Marine Debris Shoreline Survey Field Guide. U. S. National Oceanic and Atmospheric Administration Marine Debris Program. 19 p.

20. Tham Huey Yee (2019). The Distribution of Macro-, Meso- and Microplastic on Selected Marine Park Beaches in Malaysia. An unpublished BSc. thesis. School of Biological Sciences, USM. 68pp.

21. Zaity S.M.O., Lee, A.J. and Muhammad Amiruddin A. (2020). Marine Macro- and Microplastic Litter along the coastal area of Kuala Perlis. International Conference on Humanities (ICH 2019). European Proceedings of Social and Behavioural Sciences (EpSBS): 303-312. e-ISSN: 2357-1330. DOI: 10.15405/epsbs.2020.10.02.28 